\title{
Effect of gluten on the properties of ternary biopolymers based on gluten, whey protein concentrate, and kaolinite
}

\author{
Marta Wesołowska-Trojanowska ${ }^{1}$ Marta Tomczyńska-Mleko ${ }^{2}$. \\ Konrad Terpiłowski ${ }^{3} \cdot$ Bartosz Sołowiej $^{4} \cdot$ Maciej Nastaj $^{4} \cdot$ Stanisław Mleko $^{4}$
}

Received: 8 May 2017 / Revised: 22 August 2017 / Accepted: 2 September 2017 / Published online: 3 October 2017

(C) Springer-Verlag GmbH Germany 2017

\begin{abstract}
The aim of the research was to investigate the effect of different gluten ( $\mathrm{Gl})$ concentration on ternary biopolymers with whey protein concentrate (WPC) and kaolinite (KAO). Distilled water dispersions of Gl (10-30\%), WPC (7\%), and $\mathrm{KAO}(5 \%)$ were heated at $80^{\circ} \mathrm{C}$ for $30 \mathrm{~min}$. The concentration of WPC and KAO was based on previous research with montmorillonite. Rheological properties of produced wet biopolymers were evaluated by dynamic rheology and ultrasound viscometry. The obtained biopolymers were dried in the thermostatic cabinet for $24 \mathrm{~h}$ at $45^{\circ} \mathrm{C}$.
\end{abstract}

Marta Wesołowska-Trojanowska

marta.wesolowska-trojanowska@up.lublin.pl

Marta Tomczyńska-Mleko

martamleko@tlen.pl

Konrad Terpiłowski

terpil@ poczta.umcs.lublin.pl

Bartosz Sołowiej

bartosz.solowiej@up.lublin.pl

Maciej Nastaj

mnasty@tlen.pl

Stanisław Mleko

dairywhey@tlen.pl

1 Department of Biotechnology, Human Nutrition and Food Commodity Science, University of Life Sciences, Skromna 8, 20-704 Lublin, Poland

2 Institute of Plant Genetics, Breeding and Biotechnology, University of Life Sciences in Lublin, Akademicka Street 15, 20-950 Lublin, Poland

3 Department of Physical Chemistry-Interfacial Phenomena, Maria Curie Skłodowska University, M. Curie Skłodowska Sq. 3, 20-031 Lublin, Poland

4 Department of Milk Technology and Hydrocolloids, University of Life Sciences in Lublin, Skromna 8, 20-704 Lublin, Poland
The texture was determined using the puncture test and the microstructure was analyzed by scanning electron microscopy. Surface properties of dried biopolymers were analyzed by surface wettability and roughness measurements. The increase in gluten concentration caused an increase in moduli and viscosity of the obtained wet biopolymers and in the puncture force for dry biopolymers. For the ternary biopolymer, layers with intercalation and exfoliation are observed in comparison with the biopolymer obtained without KAO. With the increasing Gl content in the biopolymer, the number of surface hydrophobic groups with carbon decreased and the number of surface hydrophilic groups increased. Higher Gl concentration produced less porous structure, although there are differences in the micro and nano-scale roughness. Water contact angle decreased with the increased Gl concentration, which is in agreement with less porous microstructure of the surface. The apparent surface free energy increased with the increasing of Gl concentration. The best plastic properties and the best shape of a pot were obtained for the ternary biopolymer with the $15 \%$ Gl concentration.

Keywords Biopolymer · Gluten · Kaolinite · Microstructure $\cdot$ Surface properties $\cdot$ Whey protein

\section{Introduction}

Wheat gluten is a by-product of starch industry. The water insoluble fractions of the wheat proteins are prolamins and glutelins. In wheat, the prolamin fraction is called gliadin and the glutelin proteins are referred to as glutenin. Prolamins and glutenins represent about 33 and $46 \%$ of the total protein content in wheat, respectively. Prolamins are responsible for the viscosity of gluten and the fibrous 
glutelins affect its elasticity and firmness [1]. Wheat gluten is a material very suitable for biodegradable products as it is fully decomposed within 50 days under the aerobic soil fermentation conditions [2].

Kaolinite is an aluminosilicate with a layered structure. Its chemical formula is $\mathrm{Al}_{2} \mathrm{Si}_{2} \mathrm{O}_{5}(\mathrm{OH})_{4}$. Each layer is composed of one tetrahedral siloxane surface and an octahedral gibbsite $\left(\mathrm{Al}(\mathrm{OH})_{3}\right)$ sheet. Hydrogen bonds are responsible for binding the layers. Kaolinite is characterized by the heterogeneous surface charge with different surface structures between the base and edge planes. Charge on the edges depends on the $\mathrm{pH}$ of the solution and charge of the basal surfaces is constant due to the isomorphous substitution of $\mathrm{Si}^{4+}$ by $\mathrm{Al}^{3+}[3]$.

Whey proteins are the constituents of milk and byproducts of cheese industry. They have excellent nutritional and functional properties which are used for obtaining many different food products [4]. Lately, some no-food applications of whey proteins were made [5]. There is very little information on products obtained from gluten and whey proteins. Bakery industry uses different sources of protein to enhance nutritional values of its products. Heat treatment has a different impact on individual proteins and their interactions, especially one with another, which can be characterized as a co-protein effect. Lambrech et al. [6] developed a model to predict potential co-protein effects in the mixtures of gluten and globular proteins during heating. They detected a negative co-protein effect with the addition of lysozyme, no co-protein effect with soy glycinin or egg yolk and positive co-protein effects with bovine serum albumin, (S-)ovalbumin, egg white, whole egg, defatted egg yolk, wheat albumins, and wheat globulins. They concluded that the level of accessible-free sulfhydryl groups and the surface hydrophobicity of unfolded globular proteins were responsible for the co-protein effects in the mixtures with gluten [6].

Traditional packaging materials obtained from petroleum oil are easy to produce and cheap, but they are neither recyclable nor safe due to possible harmful additives migration [7]. Lately a lot of attention has been paid to bioplastics as an environmentally safe alternative of conventional materials. Some new products have been developed based on gluten and nanoclays. Paperboard with the coating consisting of montmorillonite sandwiched between two layers of gluten formed a very resistant barrier for oxygen and water vapor [8]. Tunc et al. [9] obtained WG/MMT nanocomposite films. The addition of MMT led to a different protein network structure, resulting in significant reduction of water sensitivity and increase in tensile strength. Similar results were obtained for the films from wheat gluten matrix and montmorillonite intercalated with different quaternary ammonium salts [10]. Mascheroni et al. [11] produced an antimicrobial film from wheat gluten as a matrix, montmorillonite as a structure enforcing agent, and carvacrol as an antimicrobial compound.

In our previous research, we obtained biopolymers based on whey protein concentrate and montmorillonite, as well as gluten, whey protein concentrate, and montmorillonite [12, 13]. They were applied to obtain pottery with the mechanical properties similar to those of natural clay. They are fully biodegradable. Proteins are hydrolyzed by natural proteases which are produced by microorganisms in soil, and montmorillonite is a constituent of soil.

In the present investigation, ternary biopolymer based on gluten, whey protein concentrate, and kaolinite was prepared. In contrast to montmorillonite, kaolinite is a nonswelling aluminosilicate with no expansion of the interlayer in water [14], which can influence the properties of the obtained biopolymer. Thus, more attention is paid to the surface properties of the obtained biopolymers. Contact angles of the probe liquids on the dried biopolymer surfaces, surface roughness, and X-ray photoelectron spectroscopy analysis were used to elucidate the influence of gluten concentration on the surface properties of the obtained biopolymers. This kind of combined surface research was for the first time used for biopolymers.

\section{Materials and methods}

\section{Materials}

Wheat gluten (WG) powder was produced by Massive (Czechowice-Dziedzice, Poland). According to the product data sheet, the powder consists of $84.1 \%$ protein, $7.8 \%$ starch, $1.51 \%$ fat, $0.69 \%$ ash, and $5.5 \%$ water. The whey protein concentrate (WPC) with $80.0 \%$ protein and $3.4 \%$ ash was obtained from SM Spomlek (Radzyń Podlaski, Poland). Kaolinite (Lot\# BCBM2772V) was purchased from SigmaAldrich, Co. (St. Louis, MO, USA).

\section{Production of biopolymers}

The wheat gluten was mixed with the whey protein concentrate and kaolinite in the plastic bags. The powder was hydrated in distilled water to obtain dispersions with 7\% $(\mathrm{w} / \mathrm{w})$ protein from WPC, $5 \%(\mathrm{w} / \mathrm{w}) \mathrm{KAO}$ and gluten in the concentrations: $10,15,20,25$ or $30 \%(\mathrm{w} / \mathrm{w})$. WPC protein and KAO concentration have been chosen based on the previous research results with montmorillonite [13]. The dispersions were heated in the water bath for $30 \mathrm{~min}$ at $80^{\circ} \mathrm{C}$. After heating, the samples were immediately cooled down with cold tap water for $10 \mathrm{~min}$. The obtained biopolymers in the form of cylinders (ca. $50 \mathrm{~mm}$ in diameter and $25 \mathrm{~mm}$ high) were stored at $7{ }^{\circ} \mathrm{C}$ for $18 \mathrm{~h}$. All the samples were equilibrated at $21^{\circ} \mathrm{C}$ for $3 \mathrm{~h}$ and subjected to determinations 
of their physicochemical properties. To obtain a dry biopolymer material, small pot shapes were formed. At the pot shaping process, three independent investigators were involved, observing how the ingredients influence the texture of material and the possibility to obtain a desired shape. Obtained shapes were dried in a thermostatic cabinet ST3/3 (Pol-Eko-Aparatura, Wodzisław Śląski, Poland) for $72 \mathrm{~h}$ at $40{ }^{\circ} \mathrm{C}$. The final water content in the sample was in the range $12.8-16.0 \%$ and it was measured by drying the samples at $105^{\circ} \mathrm{C}$ to the constant mass.

\section{Dynamic oscillatory rheology}

All rheological measurements were performed using the RS300 (ThermoHaake, Karlsruhe, Germany) rheometer with a serrated parallel steel plate geometry $(35 \mathrm{~mm}$ diameter, $2 \mathrm{~mm}$ gap size) to limit potential sliding effects. The samples were cut by a surgical scalpel $(35 \mathrm{~mm}$ in diameter and $2.5 \mathrm{~mm}$ high) and analyzed by frequency sweeps in the range $0.1-10 \mathrm{~Hz}$ in the linear viscoelastic region (at 0.01 strain determined previously by strain sweeps). All the measurements were performed at $21^{\circ} \mathrm{C}$.

\section{Ultrasound viscosity measurements}

An ultrasound viscometer Unipan type 505 (UNIPAN, Warsaw, Poland) probe was immersed into the samples. The value of viscosity $\times$ density in $\mathrm{mPas} \times \mathrm{g} / \mathrm{cm}^{3}$ was measured. Each result was the average of six measurements.

\section{Puncture tests}

Measurements were performed on dried samples (flat bottom of the pots) using a $\mathrm{P} / 2 \mathrm{~N}$ needle probe ( $2 \mathrm{~mm}$ diameter). The samples were analyzed on a $15-\mathrm{mm}$ thick metal plate with a 10-mm diameter hole in the center and a crosshead speed of $1 \mathrm{~mm} / \mathrm{s}$. The upper surface of a dried sample was fixed by a $3 \mathrm{~mm}$ steel plate with a $10-\mathrm{mm}$ diameter hole in the center to prevent the sample warping. The samples were $2.0 \mathrm{~mm}$ thick in the test area and this was measured using a micrometer with an accuracy of $0.01 \mathrm{~mm}$. Three measurements were carried out to obtain each result.

\section{Surface roughness}

The dried biopolymer surface was observed using an optical profilometer GT Contour Surface Metrology (Veeco, Tucson, USA). Surface roughness was determined using the Vision64 computer program (Veeco, Tucson, USA).

\section{Contact angles measurements}

Advancing and receding contact angles of the probe liquids on the dried biopolymer surfaces were measured using the contact angle meter GBX (Romans sur Isere, France) equipped with the controlled temperature and humidity measuring chamber as well a digital camera. The measurements were conducted at $20{ }^{\circ} \mathrm{C}$ and $50 \%$ relative humidity. A $6-\mu \mathrm{L}$ droplet from a syringe was gently settled on the sample surface by means of an automatic deposition system. The advancing contact angle was estimated from the droplet shape by the computer program Win Drop++. Then $2 \mu \mathrm{L}$ of the droplet volume was sucked into the syringe and the receding contact angle was calculated by the above mentioned program. The advancing and receding contact angles were measured for up to 10 droplets of each probe liquid [15].

\section{Apparent surface free energy determination}

In the first step, the equilibrium contact angle from the Tadmor theory was calculated [16]. Tadmor proposed the calculation of equilibrium contact angle using Eq. (1).

(A)

$$
\begin{aligned}
& \text { (A) } \Gamma_{\mathrm{a}} \equiv\left(\frac{\sin ^{3} \theta_{\mathrm{a}}}{\left(2-3 \cos \theta_{\mathrm{a}}+\cos ^{3} \theta_{\mathrm{a}}\right)}\right) ; \\
& \text { (B) } \Gamma_{\mathrm{r}} \equiv\left(\frac{\sin ^{3} \theta_{\mathrm{r}}}{\left(2-3 \cos \theta_{\mathrm{r}}+\cos ^{3} \theta_{\mathrm{r}}\right)}\right) ; \\
& \text { (C) } \theta_{\mathrm{a}} \equiv \arccos \left(\frac{\Gamma_{\mathrm{a}} \cos \theta_{\mathrm{a}}+\Gamma_{\mathrm{r}} \cos \theta_{\mathrm{r}}}{\Gamma_{\mathrm{a}}+\Gamma_{\mathrm{r}}}\right),
\end{aligned}
$$

where $\Gamma_{\mathrm{a}}$ the advancing angle weight coefficient, and $\Gamma_{\mathrm{r}}$ the receding angle weight coefficient [17].

In this paper, two approaches are applied. The first one is the approach proposed by van Oss, Good and Chaudhury (LWAB) [18] where the energy is determined from the advancing contact angles of one apolar and two polar liquids.

$W_{\mathrm{A}}=\gamma_{1}\left(1+\cos \theta_{\mathrm{eq}}\right)=2 \sqrt{\gamma_{\mathrm{s}}^{\mathrm{LW}} \gamma_{1}^{\mathrm{LW}}}+2 \sqrt{\gamma_{\mathrm{s}}^{+} \gamma_{1}^{-}}+2 \sqrt{\gamma_{\mathrm{s}}^{-} \gamma_{1}^{+}}$,

where $W_{\mathrm{A}}$ the work of adhesion, $\gamma_{1}$ the liquid surface tension, $\theta_{\mathrm{eq}}$ the contact angle (equlibrium), $\gamma_{\mathrm{s} / 1}^{\mathrm{LW}}$ the solid and liquid apolar Lifshitz-van der Waals interactions, $\gamma_{\mathrm{s} / 1}^{+}$the solid and liquid electron acceptor parameter of surface free energy, and $\gamma_{\mathrm{s} / 1}^{-}$the solid and liquid electron donor parameter of surface free energy. However, using this approach in the case of hydrophobic surfaces often gives negative values of the square root for polar parameters, usually the 

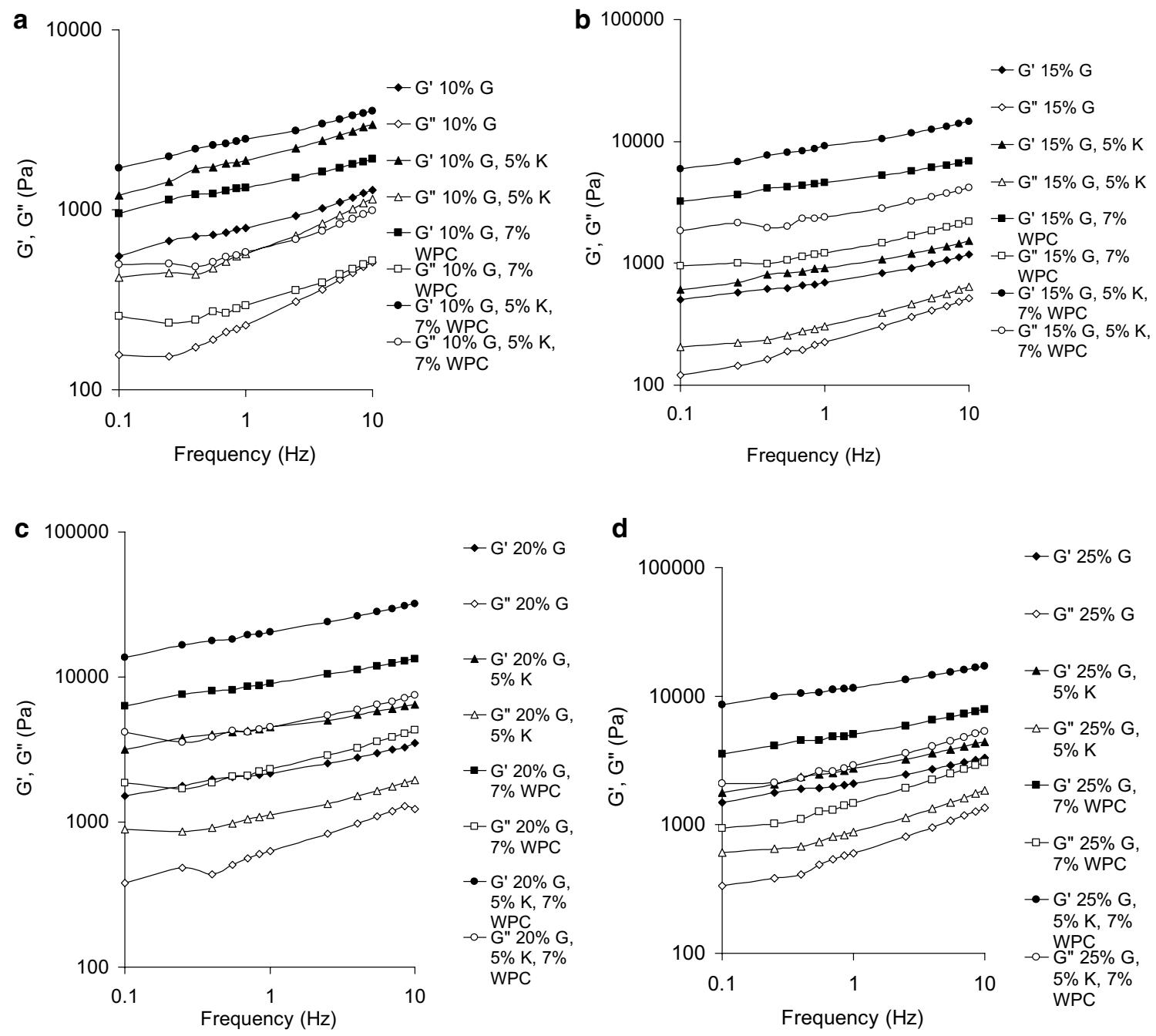

- G' $20 \%$ G

$\diamond$ G" $20 \%$ G

$7 \%$ WPC

- - G" $20 \%$ G, $7 \%$ WPC

$\rightarrow \mathrm{G}^{\prime} 20 \% \mathrm{G}$,

$5 \% \mathrm{~K}, 7 \%$

WPC

$5 \% \mathrm{~K}, 7 \%$

WPC d

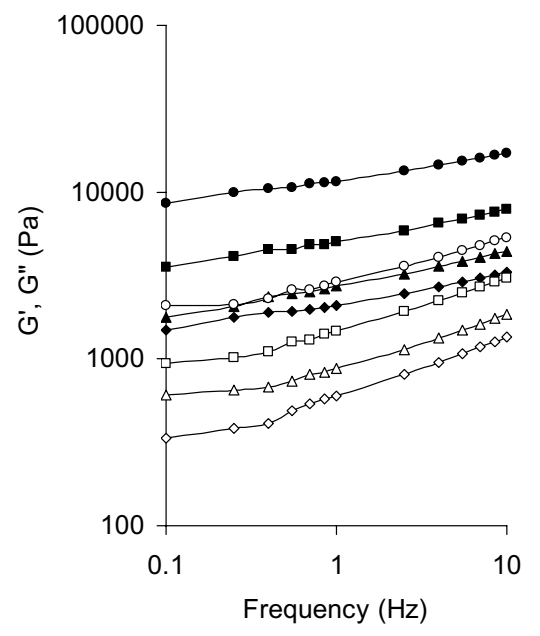

$\bullet \mathrm{G}^{\prime} 25 \% \mathrm{G}$

$\prec$ G" $25 \%$ G

$-\mathrm{G}^{\prime} 25 \% \mathrm{G}$,

$5 \% \mathrm{~K}$

$\triangle$ G" $25 \%$ G, $5 \% \mathrm{~K}$

- G' $25 \%$ G, $7 \%$ WPC

$\neg-$ G" 25\% G, $7 \%$ WPC

- $\mathrm{G}^{\prime} 25 \% \mathrm{G}$, $5 \% \mathrm{~K}, 7 \%$ WPC

$5 \% \mathrm{~K}, 7 \%$ WPC

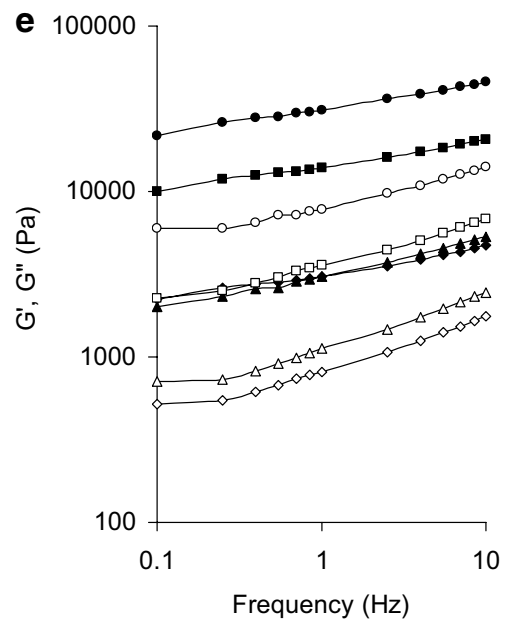

$\bullet-G^{\prime} 30 \%$ G

$\neg$ G" $30 \%$ G

$-\mathrm{G}^{\prime} 30 \% \mathrm{G}$ $5 \% \mathrm{~K}$

$\triangle$ G" $30 \%$ G, $5 \% \mathrm{~K}$

- $\mathrm{G}^{\prime} 30 \% \mathrm{G}$,

$7 \%$ WPC

$\neg-$ G" 30\% G $7 \%$ WPC

- $\mathrm{G}^{\prime} 30 \% \mathrm{G}$, $5 \% \mathrm{~K}, 7 \%$

- WPC $30 \%$ G,

$5 \% \mathrm{~K}, 7 \%$

WPC

Fig. 1 Influence of frequency on storage and loss moduli for mixed gels obtained from gluten (G), kaolinite (K), and whey protein concentrate (WPC) 


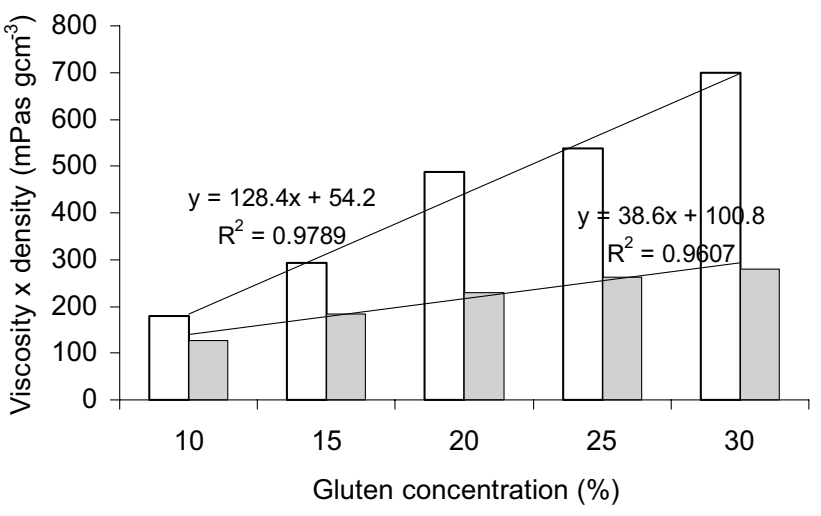

Fig. 2 Ultrasound measured viscosity $\times$ density for gels obtained from gluten and $7 \%(\mathrm{w} / \mathrm{w})$ whey protein concentrate (gray) and from gluten, $7 \%(\mathrm{w} / \mathrm{w})$ whey protein concentrate, and 5\% kaolinite (open)

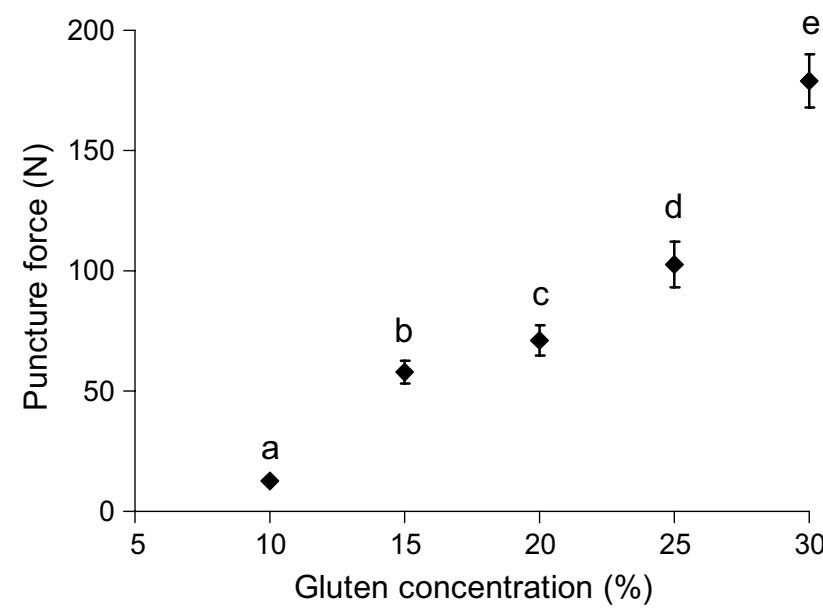

Fig. 3 Influence of gluten concentration on puncture force for dry biopolymers

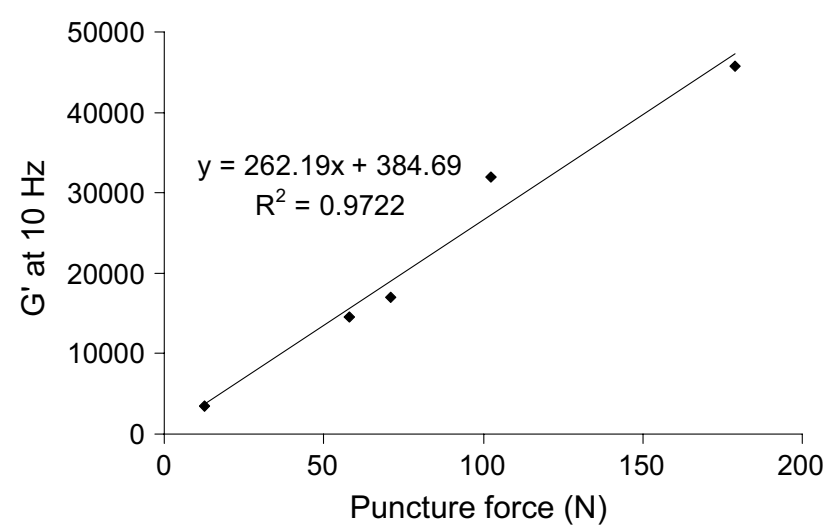

Fig. 4 Correlation between puncture force for dry biopolymers and storage value for gels measured at $10 \mathrm{~Hz}$

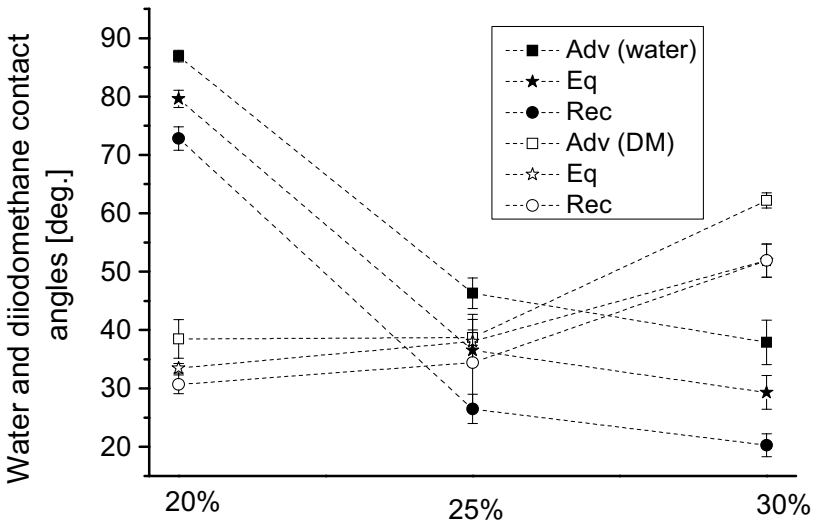

Fig. 5 Water and diiodomethane contact angles as gluten concentration function in ternary biopolymers

electron-acceptor ones. Such result does not make any sense from a physicochemical point of view and then the total surface free energy is actually expressed by the dispersion component only.

Another approach proposed by Chibowski [19] is based on the contact angle hysteresis ( $\mathrm{CAH})$.

$\gamma_{\mathrm{s}}=\frac{\gamma_{1}\left(1+\cos \theta_{\mathrm{a}}\right)^{2}}{2+\cos \theta_{\mathrm{r}}+\cos \theta_{\mathrm{a}}}$,

where $\gamma_{\mathrm{s}}$ the apparent surface free energy, $\gamma_{1}$ the liquid surface tension, $\theta_{\mathrm{a}}$ the advancing contact angle, and $\theta_{\mathrm{r}}$ the receding contact angle.

The apparent surface free energy is calculated from Eq. (3) using the advancing, and receding contact angles, and the liquid surface tension. The calculated free energy value depends somewhat on the physicochemical properties of the liquid used. When the equilibrium contact angles were used to calculate apparent surface free energy, Eq. (3) transforms into Eq. (4).

$\gamma_{\mathrm{s}}=\frac{\gamma_{1}}{2}\left(1+\cos \theta_{\mathrm{Eq}}\right)$,

where $\gamma_{1}$ the liquid surface tension, and $\theta_{\mathrm{Eq}}$ the equilibrium contact angle.

\section{Scanning electron microscopy (SEM)}

Dried biopolymers were fixed in the $2.5 \%$ glutaraldehyde solution in $0.1 \mathrm{M}$ sodium cacodylate buffer. The samples were dehydrated in serial dilutions of ethanol and acetone and dried at the critical point in liquid carbon dioxide. The preparations were coated with gold using a vacuum evaporator EMITECH K550x (Emitech, Ashford, United Kingdom). The samples were viewed and photographed using a scanning electron microscope JEOL JXA-8230 (Tokyo, Japan). 
Table 1 Contribution of individual atoms on ternary biopolymer surface with different gluten concentration

\begin{tabular}{lrrr}
\hline \%At conc. & $20 \%$ & $25 \%$ & $30 \%$ \\
\hline $\mathrm{C}$ & 80.4 & 78.6 & 75.1 \\
$\mathrm{O}$ & 16.6 & 15.9 & 18.8 \\
$\mathrm{~N}$ & 2.3 & 3.7 & 4.7 \\
$\mathrm{P}$ & 0.8 & 0.6 & 0.5 \\
$\mathrm{Si}$ & & 1.3 & 0.5 \\
$\mathrm{~S}$ & & & 0.5 \\
\hline
\end{tabular}

Table 2 Contribution of functional groups on ternary biopolymer surface with different gluten concentration

\begin{tabular}{lllll}
\hline Spectra & Functional group & $20 \%$ & $25 \%$ & $30 \%$ \\
\hline C 1s & C-C, C-H & 69.6 & 65.9 & 54.1 \\
& C-OH, C-O-C, C-N & 19.6 & 22.8 & 29.3 \\
& C=O & 6.8 & 7.6 & 10.1 \\
& COO- & 4 & 3.7 & 6.5 \\
O 1s & C=O & 26.2 & 21.7 & 24.1 \\
& C-O & 55.4 & 65.1 & 53.7 \\
& O=C-O- & 18.4 & 13.2 & 22.1 \\
N 1s & Amine & 87.5 & 75.6 & 84.2 \\
& Quaternary & 5.1 & 10 & 15.8 \\
& N-O & 7.4 & 14.4 & \\
P 2p & $\left(\mathrm{PO}_{4}\right)^{3-},\left(\mathrm{P}_{2} \mathrm{O}_{7}\right)^{4-}$ & 100 & 100 & 100 \\
S 2p & $\mathrm{S}(0), \mathrm{C}-\mathrm{S}-\mathrm{C}, \mathrm{C}-\mathrm{SH}^{\mathrm{n}}$ & & & 58 \\
& $\mathrm{R} 2-S O^{2-}$ & & & 19.1 \\
& $\left(\mathrm{SO}_{4}\right)^{2-}$ & & & 22.9 \\
\hline
\end{tabular}

\section{XPS (X-ray photoelectron spectroscopy) analysis}

XPS spectra were taken by a multi-chamber UHV analytical system Prevac which is designed to test the surface properties of solids and powdered solids, in a wide range of temperatures and pressures. Photoelectron spectroscopy (XPS) of the induced monochromatic (source MX-650's Gammadata Scienta, Al-K $\alpha$ anode) or achromatic X-rays (anode: $\mathrm{Mg} / \mathrm{Al}$ or $\mathrm{Ag}$ ) was used.

\section{Statistical analysis}

Standard deviation calculations and analysis of variance were performed using the statistical program STATISTICA 5.0 PL (StatSoft Polska, Warsaw, Poland). The significance of differences between the meanings was determined using the Tukey's test at the confidence level of $p \leq 0.05$ based on the least significant difference.

\section{Results and discussion}

\section{Rheological properties}

Figure 1 shows the influence of frequency on storage and loss moduli for the biopolymers obtained from different combinations of ingredients. The lowest values of the moduli were observed for the heated gluten dispersions. The addition of WPC or kaolinite caused an increase in the measured values. Zolfi et al. [20] found that incorporation of montmorillonite (MMT) significantly affected the mechanical properties of the kefiran-WPI films. The tensile strength and Young's modulus increased and the percentage of elongation at break decreased as the MMT content increased. The highest moduli values were noted for the biopolymers obtained from the combination of gluten, WPC, and kaolinite (Fig. 1). Increase in gluten concentration caused an increase in the moduli values. In all cases, the value of storage modulus was several times higher than the loss modulus and the increase in frequency caused an increase in moduli values. This is characteristic of physical gels with strong interactions between different ingredients. No breaking of the bonds was observed at high frequency when more energy is put into the sample. An increase in the gluten concentration caused also a linear increase in viscosity times density measured using an ultrasound viscometer (Fig. 2). Higher measured values were observed for the ternary biopolymers compared to those obtained from gluten and WPC.

\section{Textural properties}

Biopolymers obtained after heating in the water bath for $30 \mathrm{~min}$ at $80^{\circ} \mathrm{C}$ were dried in a thermostatic cabinet for $24 \mathrm{~h}$ at $45{ }^{\circ} \mathrm{C}$. The puncture test was applied to measure their textural properties (Fig. 3). The samples with higher gluten concentration broke at higher force values. Figure 4 presents the strong linear correlations between the puncture force and the storage modulus measured at the highest value of frequency $(10 \mathrm{~Hz})$. This means that the structure obtained at heating in the water bath is strengthened in the drying process and gluten is the main ingredient responsible for rheological properties of the biopolymers matrix. Apichartsrangkoon and Ledward [21] noticed that the large size gluten proteins exhibited the strengthening effect of high pressure-treated gluten-soy mixtures.

\section{Surface properties of biopolymers}

Contact angles of probe liquids were measured on the ternary biopolymer plates with the gluten concentrations $20-30 \%$. In the case of lower concentration of gluten, liquids 
Fig. 6 3D images, roughness parameters, and side profiles obtained along white line of a $20 \%$ gluten, b $25 \%$ gluten, c $30 \%$ gluten concentration
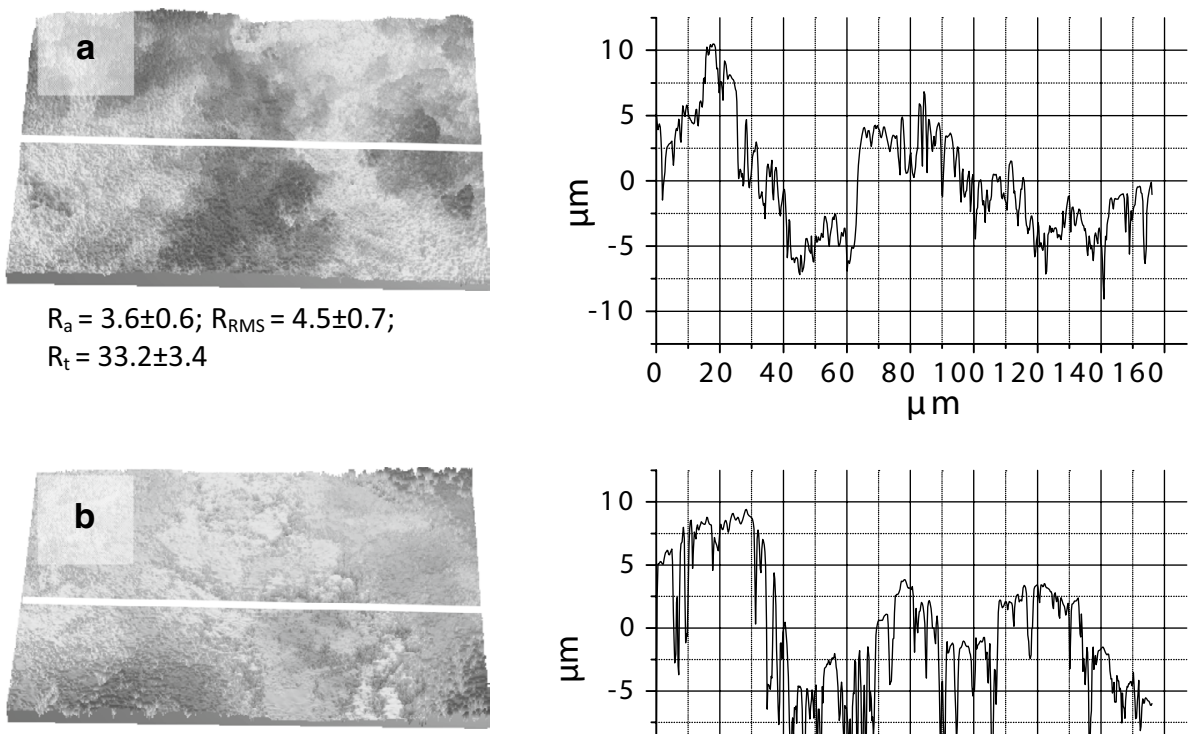

$R_{a}=5.1 \pm 1.5 ; R_{R M S}=6.8 \pm 2.4 ;$ $R_{t}=8.2 \pm 1.7$
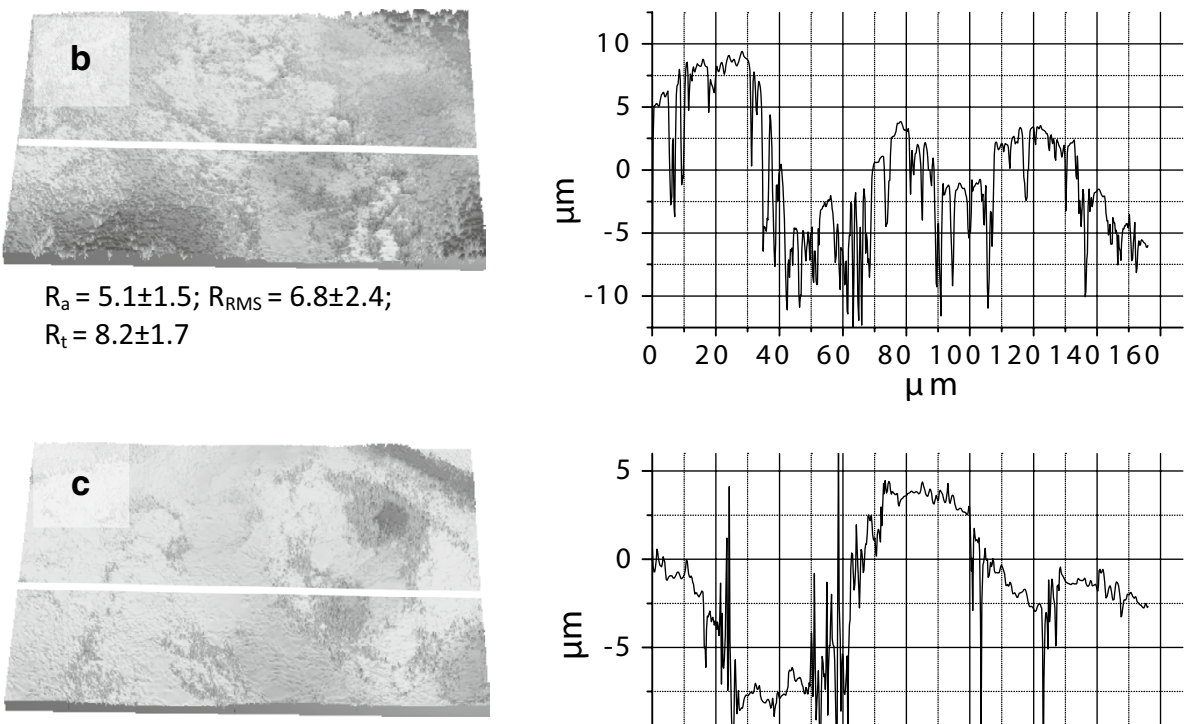

$\mathrm{R}_{\mathrm{a}}=3.9 \pm 0.6 ; \mathrm{R}_{\mathrm{RMS}}=4.9 \pm 0.7$; $\mathrm{R}_{\mathrm{t}}=37.2 \pm 3.4$

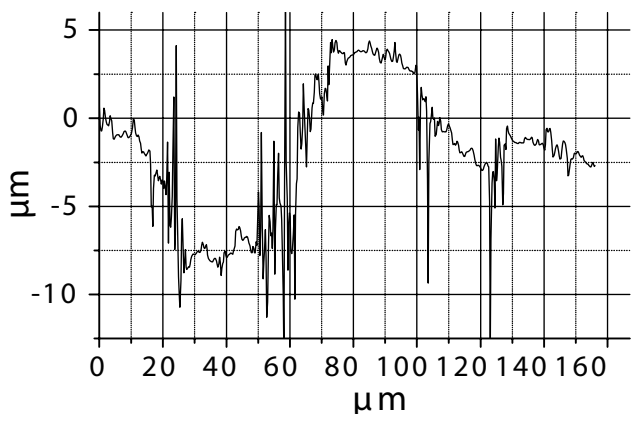

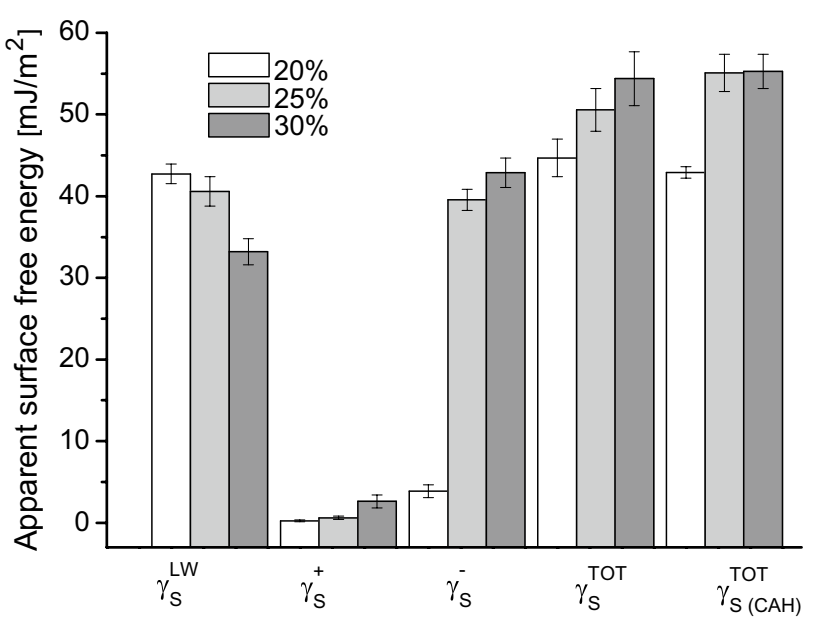

Fig. 7 Apparent surface free energy and its components calculated from LWAB and CAH approaches for biopolymers with different gluten concentration soaked into the surfaces. To determine biopolymer plates wettability, advancing and receding contact angles of water, formamide, and diiodomethane were measured. In Fig. 5, the contact angles of water and diiodomethane are given. Water is a liquid which interacts with the surface both in the dispersive and polar ways and diiodomethane interacts with the surface only in the dispersive way. Formamide contact angles are between those for water and diiodomethane (not shown). With the increasing gluten concentration, the surface becomes more hydrophilic, and water contact angle decreases from $86.9^{\circ} \pm 1.0^{\circ}$ for the surface with $20 \%$ gluten concentration to $37.9^{\circ} \pm 3.8^{\circ}$ for that with $30 \%$ gluten concentration. The opposite situation takes place in the case of non-polar diiodomethane. The contact angle measured on the $20 \%$ gluten ternary biopolymer surface is about $38.5^{\circ} \pm 3.3^{\circ}$ and increases to $62.2^{\circ} \pm 1.3^{\circ}$ for the surface with $30 \%$ gluten concentration. Surface wettability is a result of many factors: the functional group presence on the surface, surface topography, and conditions in the measurement chamber. In the case of surface composition, XPS measurement shows that increasing the gluten content in the biopolymer, the carbon 

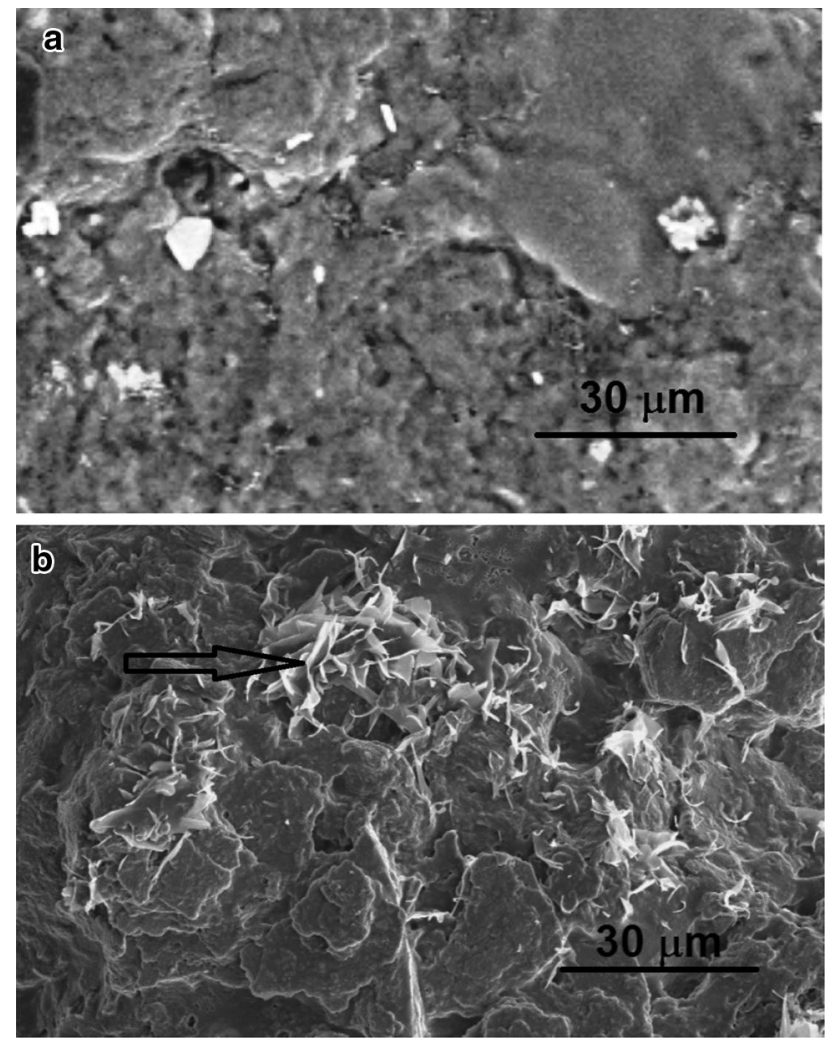

Fig. 8 Scanning electron micrographs of dry biopolymers obtained from $15 \%(\mathrm{w} / \mathrm{w})$ gluten and $7 \%(\mathrm{w} / \mathrm{w})$ WPC (a) and $15 \%(\mathrm{w} / \mathrm{w})$ gluten and 7\% (w/w) WPC and 5\% (w/w) kaolinite (b)

concentration on the surface decreases (Table 1). Carbon is present on the surface as $\mathrm{C}-\mathrm{C}$ and $\mathrm{C}-\mathrm{H}$ groups (Table 2) and in all cases this is more than $50 \%$ of the whole amount. The carbon presence in this form changes with the increasing gluten concentration. These groups are hydrophobic and hydrophobicity of the surface decreases is confirmed by the water contact angles (Fig. 5). In Table 2, one can see that carbon in the $\mathrm{C}=\mathrm{O}$ form increases. This group is hydrophilic. Taking into account the surface composition obtained from XPS, it can be concluded, that with the increasing gluten concentration, hydrophobic properties of the surface should decrease. It is confirmed by the water contact angles (Fig. 5). As it was mentioned before, surface wettability depends on many factors, but two are the most important: the functional group presence on the surface and topography. The images of surface roughness with the side profiles are given in Fig. 6. As can be seen from the images, all surfaces should be considered as rough. However, roughness structures are different for different gluten concentrations. In the case of surface with the gluten concentration $20 \%$, the hierarchical structure of roughness is present. "Hierarchical structure" is a term used in surface science. This kind of structure provides multilayers of surface roughness in micro- and nano-scale [22]. E.g., surface can be rough in a micro-scale, but it is composed of hills and holes which have smooth surface. Such a surface is not hierarchical as underneath of a microroughness there is not a nanoroughness. Side profiles obtained from profilometer reveal this kind of structure (Fig. 6).

In Fig. 6a, from the side profile, the major micro roughness structure can be seen. It is not dominated by hills and holes of nano roughness microstructure known from superhydrophobicity [23, 24]; however, biopolymer surface is hydrophilic and rough structure can only increase the value of water contact angle (Fig. 5). Without the presence of hydrophobic functional groups on the surface, it is impossible to obtain superhydrophobic properties [25]. When the gluten concentration increases to $25 \%$, a hierarchical structure can be also seen, however, in this structure nano roughness is in a different shape (Fig. 6b). It is composed of deep and narrow holes. This part of roughness cannot be accessible to water drops. As a result, water interact more with the surface micro roughness, which occurs for the $20 \%$ gluten biopolymer surface, and water contact angle decreases to $46.3^{\circ} \pm 2.6^{\circ}$ (Figs. 5, 6). At the highest gluten concentration $(30 \%)$, the surface roughness structure is mostly in the micro-scale (Fig. 6c). Water can penetrate this kind of roughness and despite the presence of some hydrophobic functional groups (Table 2), the water contact angle is low. In the case of diiodomethane, this liquid can penetrate the surface and despite changes in the roughness, the content of non-polar groups on the surface decreases (Table 2), which causes increase in diidomethane contact angles (Fig. 5). Apparent free energy was calculated using the equilibrium contact angles and two approaches [26]. Due to the change of surface composition (Tables 1,2) and surface roughness, apparent surface free energy increases with the increasing gluten concentration. The apparent surface free energy can be defined as the excess of energy on the surface of investigated material compared to the bulk of the material. In the case of investigated biopolymers, this value is important because if the value of the energy is known, it is possible to predict interactions between the material and the supportive layers. In the case of described polymers, value of energy is important in the case of interactions between the pots obtained from this material and their filling. Our calculations of apparent surface free energy were independent of the approach which was used. In Fig. 7, total apparent surface free energy, its dispersive component and polar parameters are shown. Due to the decrease of non-polar functional groups content (Table 2), the values of dispersive component of the energy decrease. We can also see increase of surface polarity because the value of both polar parameters increases. 
a

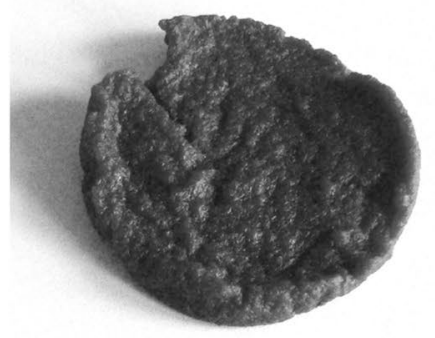

d

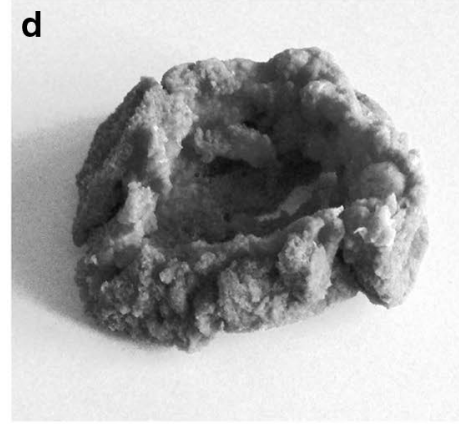

g b

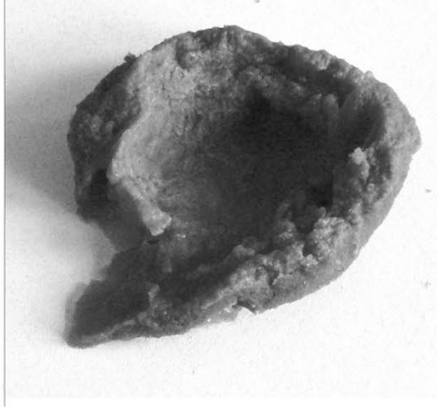

e

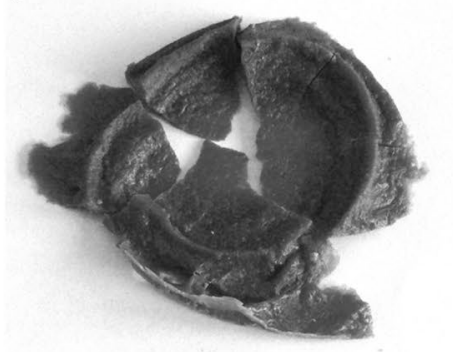

c

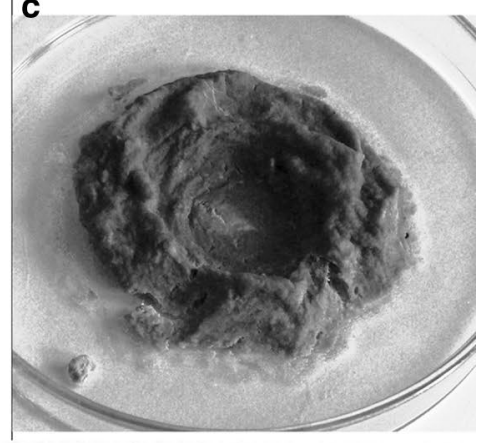

f

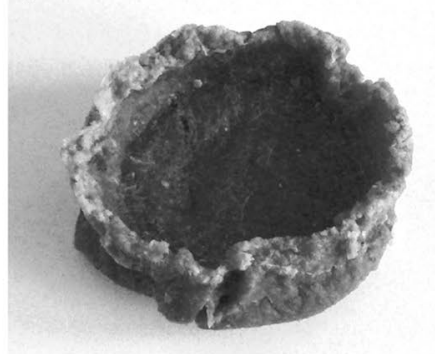

h $\quad \therefore \quad \therefore \ldots+2$
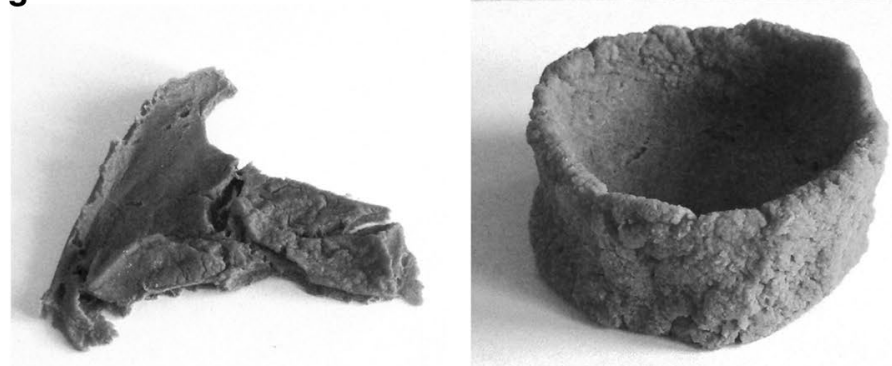

i

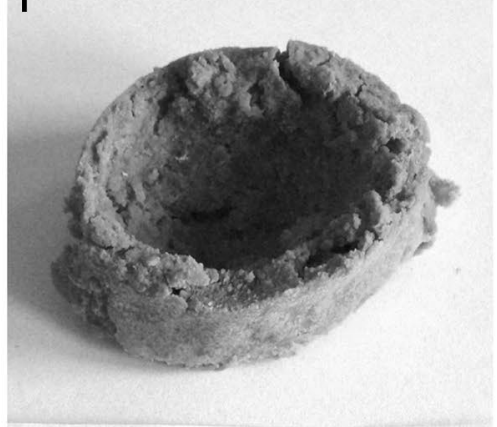

$\mathbf{k}$
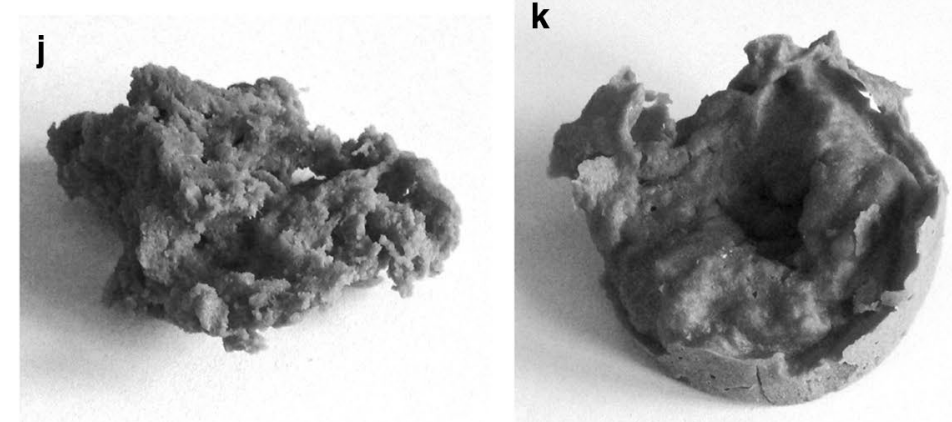

K, h $15 \%$ G, $7 \%$ WPC, $5 \%$ K, i $20 \%$ G, $7 \%$ WPC, $5 \%$ K, j 25\% G, 7\% WPC, $5 \%$ K, k 30\% G, $7 \%$ WPC, $5 \%$ K d $10 \% \mathrm{G}, 7 \%$ WPC, $5 \% \mathrm{~K}$, e $15 \% \mathrm{G}, \mathbf{f} 15 \% \mathrm{G}, 7 \%$ WPC, g $15 \% \mathrm{G}, 5 \%$

\section{Microstructure}

Figure 8 presents a comparison of the microstructure of biopolymers obtained from gluten and WPC (Fig. 8a) and

gluten, WPC and kaolinite (Fig. 8b). Kaolinite can be seen on the surface of ternary biopolymers as sticking out sharp edged particles (shown by the arrow at Fig. 8b). A similar size of the kaolinite particles was observed by Mackinnon 
et al. [27]. X-ray diffraction analysis performed by Zolfi et al. [20] showed the formation of an exfoliated structure with the addition of small amounts of MMT to the kefiran-WPI matrix. Intercalation and some exfoliation occurred up to 5\% (wt) increase in MMT. Scanning electron microscopy showed ideal dispersion of MMT nanoparticles into the structure of the biocomposite films. A similar microstructure is presented for our ternary biopolymer (Fig. 8b). For the ternary biopolymer, layers with intercalation and exfoliation are observed, compared to the biopolymer obtained without kaolinite (Fig. 8a).

\section{Pot shapes}

The main technological aim of the research was to obtain biodegradable pots. Figure 9 shows how the combination of different ingredients influences the possibility to shape wet biopolymers. The possibility to obtain a desired shape was evaluated based on independent observations of three investigators, who noted their observations. The investigators were in full agreement how the ingredients influence the texture of the material and the possibility to obtain a desired shape. Generally, wet gluten gels were very elastic and it was impossible to make a desired shape. After drying, the obtained material was very coherent and at the higher gluten concentration-extremely strong. The addition of kaolinite loosened the structure of the gel, but it was also not possible to obtain a pot shape (Fig. 9c, g). A better effect was observed for the mixtures of gluten and WPC (Fig. 9b, f). The best plastic properties to obtain a necessary shape were observed for the ternary biopolymers (Fig. 9h-k). The difference between these biopolymers was seen in gluten concentration. The best plastic properties and the best shape of a pot were obtained for the ternary biopolymer with $15 \%$ gluten concentration (Fig. 9h). Summarizing, every ingredient has a different influence on the final plastic properties of biopolymer. Gluten increases elasticity and coherence of the gel and the final dried product is more concise and harder. WPC makes the biopolymer coherent, however, the elasticity drops and it is much easier to form a desired shape. Kaolinite added to gluten loosens the microstructure, and the gel is not coherent enough to shape it. But this ingredient is necessary as it is much easier to dry gluten gels. Gluten without kaolinite has a tendency to dry fast producing a strong and coherent surface, which is wet inside. This kind of surface causes the water to be included in the gel and it is impossible to remove it. Combination of all three ingredients allows obtaining a material with plastic properties similar to natural clay.

\section{Conclusions}

The increase in the gluten concentration causes an increase in moduli and viscosity values for the obtained wet biopolymers (gels) and in the puncture force for dry biopolymers. For the ternary biopolymer, layers with intercalation and exfoliation are observed in comparison with the biopolymer obtained without kaolinite. Surface wettability is a result of the presence of the functional groups and surface topography. With the increasing gluten content in the biopolymer, the number of surface hydrophobic groups with carbon decreases and number of surface hydrophilic groups increases. As the surface becomes more hydrophilic, the water contact angle decreases. Changes in the gluten concentration cause changes in the surface roughness. A higher gluten concentration produces less porous structure, although there are differences in the micro- and nano-scale roughness. Water contact angle decreases with the increased gluten concentration, which is in agreement with a less porous microstructure of the surface. The apparent surface free energy increases with the increase of gluten concentration. It is independent of the approach which was used for the apparent surface free energy calculation. As for the application part of the research, the best plastic properties and the best shape of a pot were obtained for the ternary biopolymer with the $15 \%$ gluten concentration. This research characterizing surface properties can be important for future investigation on adhesion of different materials to the surface of biopolymers. This adhesion can influence waste of products and cleaning procedure. It also can be important in terms of adhesion of soil containing extracellular enzymes, biodegrading the biopolymers.

\section{Compliance with ethical standards}

\section{Conflict of interest None.}

Compliance with ethics requirements This article does not contain any studies with human or animal subjects.

\section{References}

1. Zink J, Wyrobnik T, Prinz T, Schmid M (2016) Physical, chemical and biochemical modification of protein-based films and coatings: an extensive review. Int J Mol Sci 17:1376

2. Patni N, Yadava P, Agarwal A, Maroo V (2014) An overview on the role of wheat gluten as a viable substitute for biodegradable plastics. Rev Chem Eng 30:421-430

3. Barral S, Villa-Garcia MA, Rendueles M, Diaz M (2008) Interactions between whey proteins and kaolinite surfaces. Acta Mater 56:2784-2790

4. Mleko S (1999) Effect of protein concentration on whey protein gels obtained by a two-stage heating process. Eur Food Res Technol 209:389-392 
5. Tomczyńska-Mleko M, Terpiłowski K, Mleko S (2015) Physicochemical properties of cellulose/whey protein fibers as a potential material for active ingredients release. Food Hydrocoll 49:232-239

6. Lambrecht MA, Rombouts I, De Ketelaere B, Delcour JA (2016) Prediction of heat-induced polymerization of different globular food proteins in mixtures with wheat gluten. Food Chem 221:1158-1167

7. Gómez-Heincke D, Martínez I, Partal P, Guerrerob A, Gallegosa C (2016) Development of antimicrobial active packaging materials based on gluten proteins. J Sci Food Agric 96:3432-3438

8. Türe H, Gällstedt M, Johansson E, Hedenqvist MS (2013) Wheatgluten/montmorillonite clay multilayer-coated paperboards with high barrier properties. Ind Crops Prod 51:1-6

9. Tunc S, Angellier H, Cahyana Y, Chalier P, Gontard N, Gastaldi E (2007) Functional properties of wheat gluten/montmorillonite nanocomposite films processed by casting. J Membr Sci 289:159-168

10. Guilherme MR, Mattoso LHC, Gontard N, Guilbert S, Gastaldi E (2010) Synthesis of nanocomposite films from wheat gluten matrix and mmt intercalated with different quaternary ammonium salts by way of hydroalcoholic solvent casting. Compos Part A Appl Sci Manuf 41:375-382

11. Mascheroni E, Chalier P, Gontard N, Gastaldi E (2010) Designing of a wheat gluten/montmorillonite based system as carvacrol carrier: rheological and structural properties. Food Hydrocoll 24:406-413

12. Kawecka-Radomska M, Tomczyńska-Mleko M, WesołowskaTrojanowska M, Kowalczyk K, Chrząstek M, Mleko S (2015) Hard biodegradable biopolymer obtained from whey protein concentrate and montmorillonite. J Polym Environ 23:534-540

13. Wesołowska-Trojanowska M, Tomczyńska-Mleko M, Terpiłowski K, Kawecka-Radomska M, Mleko S (2016) Ternary biopolymer based on wheat gluten, whey protein concentrate and montmorillonite. J Inorg Organomet Polym 26:555-562

14. Andersen A, Reardon PN, Chacon SS, Qafoku NP, Washton NM, Kleber M (2016) Protein-mineral interactions: molecular dynamics simulations capture importance of variations in mineral surface composition and structure. Langmuir 32:6194-6209

15. Rymuszka D, Terpiłowski K (2013) Influence of volume drop on surface free energy of glass. Ann Univ Mariae Curie Sklodowska Sectio AA 68:121-132
16. Tadmor R (2008) Line energy, line tension and drop size. Surface Sci 602:108-111

17. Terpiłowski K (2015) Surface free energy of superhydrophobic materials obtained by deposition of polymer particles on glass. In: Mittal KL (ed) Advances in contact angle, wettability and adhesion. CRC Press, Boca Raton

18. van Oss CJ, Roberts MJ, Good RJ, Chaudhury MK (1987) Determination of the apolar component of the surface tension of water by contact angle measurements on gels. Colloids Surf A 23:369-373

19. Chibowski E (2002) Contact angle hysteresis due to a film present behind the drop. In: Mittal KL (ed) Contact angle, wettability and adhesion, vol 2. VSP, Utrecht

20. Zolfi M, Khodaiyan F, Mousavi M, Hashemi M (2015) Characterization of the new biodegradable WPI/clay nanocomposite films based on kefiran exopolysaccharide. J Food Sci Technol 52:3485-3493

21. Apichartsrangkoon A, Ledward DA (2002) Dynamic viscoelastic behaviour of high pressure treated gluten-soy mixtures. Food Chem 77:317-323

22. Gao N, Yan YY, Chen XY, Mee DJ (2011) Superhydrophobic surface with hierarchical structure. Mater Lett 65:2902-2905

23. Khojasteh D, Kazerooni M, Salarian S, Kamali R (2016) Droplet impact on superhydrophobic surfaces: a review of recent developments. J Ind Eng Chem 42:1-14

24. Terpiłowski K (2017) Most modern techniques of superhydrophobic surface design and methods of its characterization. In: Henderson TM (ed) Superhydrophobic surfaces and coatings: Investigations and insights. Nova Science Publishers, Hauppauge

25. Drelich J, Chibowski E, Meng DD, Terpiłowski K (2011) Hydrophilic and superhydrophilic surfaces and materials. Soft Matter 7:9804-9828

26. Terpiłowski K, Rymuszka D, Hołysz L, Ilnicki M (2017) Surface properties of metal alloys used in aviation after plasma treatment. Surf Interface Anal. doi:10.1002/sia.6204

27. Mackinnon IDR, Uwins PJR, Yago A, Page D (1993) Kaolinite particle sizes in the $<2 \mu \mathrm{M}$ range using laser scattering. Clay Mineral 41:613-623 